\title{
The correlations between pulmonary function tests and polysomnographic parameters in overlap syndrome
}

\author{
๑DSezgi Şahin Duyar ${ }^{1}$, Deniz Çelik ${ }^{2}$, @Selma Furat ${ }^{1}$ \\ ${ }^{1}$ University of Health Sciences Atatürk Chest Diseases and Thoracic Surgery Education and Research Hospital, Sleep Disorders Center, Ankara, Turkey \\ ${ }^{2}$ Alanya Alaaddin Keykubat University, Faculty of Medicine, Department of Pulmonology, Antalya, Turkey
}

Cite this article as: Şahin Duyar S, Çelik D, Furat S. The correlations between pulmonary function tests and polysomnographic parameters in overlap syndrome. J Health Sci Med 2022; 5(1): 73-78.

\begin{abstract}
Aim: This study aims to reveal the relationship between Pulmonary Function Tests (PFTs) parameters and polysomnographic parameters. It aims to determine the guiding values in treatment selection, with the hypothesis that easily accessible PFTs parameters can be useful in clinical evaluation for patients with restrictive or obstructive type disorders.

Material and Method: One hundred and forty-six patients with obstructive and/or restrictive pulmonary dysfunction who underwent polysomnography in the sleep clinic of our hospital between June 2019 and December 2019 were included in the study. Polysomnography (PSG) parameters and PFTs results were obtained. Age, gender, body mass index (BMI), Epworth Sleepiness Scale (ESS) score, PFTs parameters, apnea-hypopnea index (AHI), nocturnal oxygen saturation, tolerable positive airway therapy modality, and pressures were recorded.

Results: Of 146 patients $34.9 \%$ were women and most (92.5\%) had an obstructive disorder in PFTs. Of the patients with the obstructive disorder, 71 were being followed up with a diagnosis of chronic obstructive pulmonary disease (COPD) and 64 with a diagnosis of asthma. Interstitial lung disease was observed in 5 out of 11 cases (7.5\%) with restrictive type disorder, and obesity resulted in restrictive disorder for the remaining 6 cases. Simple snoring was observed in 5.5\%. Mild OSAS was observed at a rate of 30.1\%. Moderate-severe OSAS was detected in $64.4 \%$ of the patients. When the relationship between optimal inspiratory/ expiratory positive airway pressure (IPAP/EPAP) values determined by automatic bilevel positive airway pressure (ABPAP) titration and PFTs parameters were analyzed, a moderate negative correlation was observed between IPAP value and forced vital capacity (FVC) $(\mathrm{L})(\mathrm{r}=-0.432, \mathrm{p}=0035)$

Discussion: The results of this study show that PFTs parameters can be used to predict polysomnographic findings for patients with obstructive/ restrictive disorders. Almost two-thirds of the patients with obstructive sleep apnea (OSA)-related symptoms in this group were observed to have moderate-severe obstructive sleep apnea syndrome (OSAS). Based on our results in ROC analysis, we believe that it would be appropriate to recommend titration with bilevel devices, especially for patients with forced expiratory volume in one second (FEV1) $<60 \%$ and maximum expiratory flow between $25 \%$ and $75 \%$ of $\mathrm{FVC}\left(\mathrm{MEF}_{25-75}\right)<30 \%$. Bilevel devices may be useful for patients with reduced $\mathrm{MEF}_{25-75}(\mathrm{representing}$ peripheral airways), through alveolar recruitment and pressure support.

Conclusion: In our study, we demonstrated that the optimal IPAP value for treatment had a positive correlation with the oxygen desaturation index (ODI) and $\mathrm{AHI}$ and a negative correlation with minimum finger pulse oximetry $\left(\mathrm{SpO}_{2}\right)$, as well as a negative correlation with $\mathrm{FVC}$ value. Simple spirometric data along with polysomnographic data can also be helpful when determining baseline pressures in bilevel positive airway pressure (BPAP) titration for OSAS patients with respiratory dysfunction.
\end{abstract}

Keywords: PFTs, FVC, AHI, OSAS, IPAP

\section{INTRODUCTION}

Obstructive sleep apnea syndrome (OSAS), which is characterized by a complete or partial obstruction of the upper airway during sleep, has a multifactorial etiology. It is known that craniofacial anomalies and obesity together with a decrease in lung volume play a role in its pathogenesis. The decrease in lung volumes causes a less caudal traction effect leading to the collapse in the pharyngeal airway $(1,2)$. There are also studies showing that pharyngeal collapsibility decreases as a result of negative extrathoracic pressure and lung volumes exceeding functional residual capacity (3). Increases in

respiratory system resistance, which can be measured with the forced oscillation technique (FOT), lead to an increase in OSAS severity, especially in obese patients. Changes in elastic recoil pressure, which is an important mechanical property of the lungs, are considered a liable pathway in the pathogenesis of OSAS, as the decrease in peripheral lung volumes $(4,5)$. Regarding the relationship between easily accessible spirometric values and obstructive sleep apnea (OSA), there are conflicting results in studies conducted with different patient groups $(6,7)$. In addition, pulmonary function 
test (PFTs) parameters can guide the choice of treatment in OSAS (8). Especially when OSAS is associated with respiratory disorders such as asthma, chronic obstructive pulmonary disease (COPD), and interstitial lung disease, the clinical results may deteriorate. For this group known as overlap syndrome, improvement in prognosis can be achieved and quality of life can increase with appropriate OSAS treatment (9). There is a common belief that conventional PFTs are not useful in the diagnosis of OSAS (10). However, this study aims to reveal the relationship between PFTs parameters and polysomnographic parameters. It aims to determine the guiding values in treatment selection, with the hypothesis that easily accessible PFTs parameters can be useful in clinical evaluation for patients with restrictive or obstructive type disorders.

\section{MATERIAL AND METHOD}

The ethics committee approval for this study was obtained by the University of Health sciences Keçiören Education and Training Hospital Clinical Studies Ethics Committee (Date: 14/09/2021, Decision No: 2012KAEK-15/2367). All procedures were carried out in accordance with the ethical rules and the principles of the Declaration of Helsinki.

One hundred and forty-six patients with obstructive and/or restrictive pulmonary dysfunction who underwent polysomnography in the sleep clinic of our hospital between June 2019 and December 2019 were included in the study. PFTs were performed at the time of admission to the sleep clinic. Forced expiratory volume in one second (FEV1), forced vital capacity (FVC), FEV 1/FVC, and maximum expiratory flow between 25\% and $75 \%$ of FVC $\left(\mathrm{MEF}_{25-75}\right)$ values were obtained from PFTs reports in line with the standards of American Thoracic Society (ATS)/European Respiratory Society (ERS) (11). FEV1/FVC ratio below 0.70 was defined as an obstructive disorder. FVC below $80 \%$, with a normal FEV1/FVC ratio, is defined as a restrictive disorder. Exclusion criteria included patients with a sleep time of $<180$ minutes in the polysomnography test and whose PFTs performance was not acceptable according to the ATS guideline (11).

The files of the sleep outpatient clinic and the results of polysomnography were reviewed retrospectively. Total sleep time, oxygen saturation by finger pulse oximetry $\left(\mathrm{SpO}_{2}\right)$, and apnea-hypopnea index (AHI) were obtained from the records of standard fullnight polysomnography montages with four channels of the electroencephalogram, two channels of electrooculogram, one channel of chin electromyogram, the thermistor, airflow, inductive plethysmography for thoracoabdominal motion, electrocardiography and finger pulse oximetry $\left(\mathrm{SpO}_{2}\right)$. All records were scored according to the American Academy of Sleep Medicine (AASM) Scoring Manual Version 2.2 (12).

Age, gender, body mass index (BMI), Epworth Sleepiness Scale (ESS) score, PFTs parameters, apnea-hypopnea index, nocturnal oxygen saturation, tolerable positive airway therapy modality, and pressures were recorded.

Nocturnal hypoxemia was defined as arterial oxygen saturation below $88 \%$ for at least 5 minutes during the all-night PSG test (13). Positive airway pressure (PAP) titration success was determined according to the criteria in the AASM guide (14).

\section{Statistical Analysis}

We used SPSS software version 21 for all analyses, and statistical significance was accepted as a p-value of $<0.05$. The variables were classified according to the normality tests including histograms, the ratio of the standard deviation to mean, and the The Kolmogorov-Smirnov test. The normally distributed variables were presented as mean $\pm \mathrm{sd}$. The non-normally distributed variables were presented as median (25th-75th percentile). Nominal variables presented as number(\%) were compared with a Chi-square test. Mann Whitney U test or Student-t test was performed to compare the distribution of two groups for numerical data. The receiving operator characteristic (ROC) curve analysis was used to determine a significant cut-off value for $\mathrm{SpO}_{2}, \mathrm{FEV} 1$ and $\mathrm{MEF}_{25-75}$ in predicting the titration failure, nocturnal hypoxemia and need for oxgen support during the sleep. The sensitivity, specificity, positive and negative predictive values were also presented. The correlations between expired positive airway pressure (EPAP), inspired positive airway pressure (IPAP) and the clinical variables were calculated using the Spearman test.

\section{RESULTS}

Of 146 patients $34.9 \%$ were women and most (92.5\%) had an obstructive disorder in PFTs. Of the patients with the obstructive disorder, 71 were being followed up with a diagnosis of COPD and 64 with a diagnosis of asthma. Interstitial lung disease was observed in 5 out of 11 cases $(7.5 \%)$ with restrictive type disorder, and obesity resulted in restrictive disorder for the remaining 6 cases. Moderate-severe OSAS was detected in $64.4 \%$ of the patients. Simple snoring was observed in $5.5 \%$ of this population, all of whom were symptomatic in terms of sleep apnea whilst mild OSAS was observed at a rate of $30.1 \%$.

Fourteen patients who were receiving long-term oxygen therapy at home were given $2 \mathrm{lt} / \mathrm{min}$ nasal oxygen during the PSG after recording at room air for at least 30 minutes was obtained. It was observed that for 12 of these patients 
(85.7\%), sleep-related hypoxemia persisted despite nasal oxygen support. For all patients with nocturnal hypoxemia, oxygen saturation in wakefulness $\left(\mathrm{SpO}_{2}\right.$ awake) was $\leq 92 \%$. After the exclusion of 14 patients who were given oxygen support during PSG, the data of 51 patients with sleep-related hypoxemia were compared with 81 patients who were not hypoxemic.

It was observed that patients with nocturnal hypoxemia were older, and their BMI and AHI values were higher. All of the PFTs parameters, FVC\%, FVC (L), FEV1\%, FEV1 (L), FEV1/FVC, $\mathrm{MEF}_{25-75} \%$, were found to be statistically lower for these patients.

Also, the $\mathrm{SpO}_{2}$ awake values of these patients were lower. ESS score and gender distribution were statistically similar between the groups (Table 1). Sleep-related hypoxemia was observed in $50.8 \%$ of the patients followed up with COPD and in $24.2 \%$ of the patients diagnosed with asthma. Sleeprelated hypoxemia was observed in $27.6 \%$ of patients with positional OSAS $(n=29)$ and $37 \%$ of patients with rapid eye movement (REM)-related OSAS $(n=49)$.

Regarding the population, for which restrictive or obstructive disorders were found with pulmonary function tests, half of the patients did not attend or complete the titration tests. While titration was found to be successful for 16 of 21 patients who were titrated with automatic positive airway pressure (APAP) (76.2\%); the titration test was successful for 23 (95.8\%) of 24 patients who were titrated with automatic bilevel positive airway

\begin{tabular}{|c|c|c|c|}
\hline & $\begin{array}{c}\text { Patients with } \\
\text { nocturnal } \\
\text { hypoxemia } \\
\text { n=51 } \\
\text { median } \\
\left(25^{\text {th }}-75^{\text {th }}\right. \\
\text { percentile) } \\
\text { n }(\%) \\
\text { mean } \pm \text { SD }\end{array}$ & $\begin{array}{c}\text { Patients } \\
\text { without } \\
\text { nocturnal } \\
\text { hypoxemia } \\
n=81 \\
\text { median } \\
\left(25^{\text {th }}-75^{\text {th }}\right. \\
\text { percentile) } \\
n(\%) \\
\text { mean } \pm \text { SD }\end{array}$ & $\underset{\text { value }}{\mathbf{p}}$ \\
\hline Gender (female, \%) & $21(41.2 \%)$ & $23(28.4 \%)$ & 0.129 \\
\hline Age & $58.5 \pm 9.5$ & $52.5 \pm 11$ & 0.002 \\
\hline BMI $\left(\mathrm{kg} / \mathrm{m}^{2}\right)$ & $34.3(29.7-39.1)$ & $31(27.7-34.7)$ & 0.003 \\
\hline ESS & $7(3-10)$ & $8(2.5-11)$ & 0.963 \\
\hline AHI (events/hour) & $29.6(17.3-38.4)$ & $16(9.9-36)$ & 0.005 \\
\hline ODI & $20.2(13.3-32.7)$ & $12.3(5.1-25.9)$ & 0.001 \\
\hline Awake $\mathrm{SpO}_{2}$ & $88(86-89)$ & $92(91-94)$ & $<0.001$ \\
\hline Minimum $\mathrm{SpO}_{2}$ & $69(61-76)$ & $83(77-87.5)$ & $<0.001$ \\
\hline Mean $\mathrm{SpO}_{2}$ & $87(81-87)$ & $91(89-92.5)$ & $<0.001$ \\
\hline FVC (L) & $2.2 \pm 0.76$ & $3.1 \pm 0.84$ & $<0.001$ \\
\hline FVC (\%) & $64.1 \pm 17.2$ & $79.7 \pm 17.7$ & $<0.001$ \\
\hline FEV1 (L) & $1.5 \pm 0.56$ & $2.2 \pm 0.64$ & $<0.001$ \\
\hline FEV1 (\%) & $51(42-67)$ & $72(64.5-80)$ & $<0.001$ \\
\hline FEV1/FVC & $69(61-75)$ & $73(67-77)$ & 0.013 \\
\hline $\mathrm{MEF}_{25-75}(\%)$ & $31(21-50)$ & $50(40-59)$ & $<0.001$ \\
\hline \multicolumn{4}{|c|}{$\begin{array}{l}\text { BMI: Body mass index, ESS: Epworth Sleepiness Scale, AHI: Apnea-hypopnea } \\
\text { index, ODI: Oxygen desaturation index, } \mathrm{SpO}_{2} \text { : Finger pulse oximetry, FVC: Forced } \\
\text { vital capacity, FEV1: Forced expiratory volume in one second, MEF } 25-75 \text { : Maximum } \\
\text { expiratory flow between } 25 \% \text { and } 75 \% \text { of FVC }\end{array}$} \\
\hline
\end{tabular}

pressure (ABPAP). For ten patients, despite the optimal pressure support with bilevel positive airway pressure (BPAP) therapy, additional oxygen support to provide nocturnal oxygenation was required. It was observed that the group with failed APAP titration was similar to the successful group in terms of age, $\mathrm{BMI}, \mathrm{SpO}_{2}$ awake, and ESS score, but the PFTs parameters were significantly lower (Table 2). Similarly, it was observed that the group whose oxygenation improved only with ABPAP was similar to the group in need of additional oxygen in terms of age, BMI, wakefulness $\mathrm{SpO}_{2}$ and ESS score, but all other PFTs parameters except the FEV1/FVC ratio were lower for the patients requiring additional oxygen (Table 3). With the ROC analysis, the optimal cut-off values were determined by selecting the 2 most ideal parameters according to the area under the curve (Figure 1).

FEV1 $(\mathrm{L})<1.9$ and $\mathrm{SpO}_{2}<90 \%$ for nocturnal hypoxemia; FEV $1(\mathrm{~L})<1.5$ and FEV $1 \%<50 \%$ for supplemental oxygen demand; FEV1 $\%<60 \%$ and $\mathrm{MEF}_{25-75} \%<30 \%$ for APAP titration failure, were set as statistically significant cut-off values (Figure 1-3). Sensitivity, specificity, positive and negative predictive values of these limit values are shown in Table 4. In addition, when the relationship between optimal IPAP/EPAP (inspiratory/expiratory positive airway pressure) values determined by ABPAP titration and PFTs parameters was analyzed, a moderate negative correlation was observed between IPAP value and FVC (L) $(\mathrm{r}=-0.432, \mathrm{p}=0035$, Table 5).

Table 2. The demographic and polysomnographic differences of the patients with APAP titration failure

\begin{tabular}{|c|c|c|c|}
\hline & $\begin{array}{c}\text { Succesful } \\
\text { titration with } \\
\text { APAP } \\
\mathbf{n}=16 \\
\text { median } \\
\left(25^{\text {th }}-75^{\text {th }}\right. \\
\text { percentile }) \\
\mathbf{n}(\%) \\
\text { mean } \pm \text { SD }\end{array}$ & $\begin{array}{c}\text { APAP titration } \\
\text { failure } \\
\mathbf{n}=5 \\
\text { median } \\
\left(25^{\text {th }}-75^{\text {th }}\right. \\
\text { percentile }) \\
\mathbf{n}(\%) \\
\text { mean } \pm \text { SD }\end{array}$ & $\underset{\text { value }}{p}$ \\
\hline Age & $53.9 \pm 11.3$ & $64.2 \pm 15.3$ & 0.12 \\
\hline BMI $\left(\mathrm{kg} / \mathrm{m}^{2}\right)$ & $31.2(26.3-37.7)$ & $29.7(21.7-39)$ & 0.680 \\
\hline ESS & $9.5(4.3-13)$ & $9(0-13.5)$ & 0.648 \\
\hline AHI (events/hour) & $29.9(16.2-42.1)$ & $42.6(20.8-66.9)$ & 0.28 \\
\hline ODI & $19.7(9.9-27.4)$ & $31.8(11.8-51.9)$ & 0.19 \\
\hline Awake $\mathrm{SpO}_{2}$ & $92(91-94)$ & $91(87.5-92.5)$ & 0.12 \\
\hline Minimum $\mathrm{SpO}_{2}$ & $79(68.5-89.8)$ & $85(59-91)$ & 0.97 \\
\hline Mean $\mathrm{SpO}_{2}$ & $91.5(89.3-92.8)$ & $70(68-88.5)$ & 0.006 \\
\hline FVC (L) & $3.2 \pm 0.83$ & $2.3 \pm 0.59$ & 0.042 \\
\hline FVC (\%) & $85 \pm 17.1$ & 64.23 .3 & 0.015 \\
\hline FEV1 (L) & $2.3 \pm 0.53$ & $1.4 \pm 0.39$ & 0.003 \\
\hline FEV1 (\%) & $78(66-82.8)$ & $51(48-53.5)$ & 0.001 \\
\hline FEV1/FVC & $73(71-76.8)$ & $61(58.5-65.5)$ & 0.002 \\
\hline $\mathrm{MEF}_{25-75}(\%)$ & $50.5(44.3-57)$ & $24(20-32.5)$ & 0.001 \\
\hline \multicolumn{4}{|c|}{$\begin{array}{l}\text { BMI: Body mass index, ESS: Epworth Sleepiness Scale, AHI: Apnea-hypopnea } \\
\text { index, ODI: Oxygen desaturation index, SpO } \mathrm{S}_{2} \text { : Finger pulse oximetry, FVC: Forced } \\
\text { vital capacity, FEV1: Forced expiratory volume in one second, } \mathrm{MEF}_{25-75} \text { : Maximum } \\
\text { expiratory flow between } 25 \% \text { and } 75 \% \text { of FVC, }\end{array}$} \\
\hline
\end{tabular}




\begin{tabular}{|c|c|c|c|}
\hline & $\begin{array}{c}\text { With } \\
\text { supplemental } \\
\text { oxygen } \\
n=10 \\
\text { median }\left(25^{\text {th }}-\right. \\
\left.75^{\text {th }} \text { percentile }\right) \\
n(\%) \\
\text { mean } \pm \text { SD }\end{array}$ & $\begin{array}{c}\text { Without } \\
\text { supplemental } \\
\text { oxygen } \\
n=14 \\
\text { median }\left(25^{\text {th }}\right. \\
\left.75^{\text {th }} \text { percentile }\right) \\
n(\%) \\
\text { mean } \pm S D \\
\end{array}$ & $\underset{\text { value }}{p}$ \\
\hline Age & $60.9 \pm 8.4$ & $56.4 \pm 9.4$ & 0.244 \\
\hline $\mathrm{BMI}\left(\mathrm{kg} / \mathrm{m}^{2}\right)$ & $38.9(34-46.1)$ & $34.2(30.8-39.1)$ & 0.101 \\
\hline ESS & $10(0-16.5)$ & $9.5(2-12.3)$ & 0.860 \\
\hline AHI (events/hour) & $33.3(20.4-49.2)$ & $32.2(15.8-55)$ & 0.747 \\
\hline ODI & $20.9(12.8-52.5)$ & $16.7(14.5-36)$ & 1.0 \\
\hline Awake $\mathrm{SpO}_{2}$ & $87.5(80.8-90)$ & $89(88-89.3)$ & 0.191 \\
\hline Minimum $\mathrm{SpO}_{2}$ & $61(37.5-79)$ & $73(67.5-78.3)$ & 0.135 \\
\hline Mean $\mathrm{SpO}_{2}$ & $83.5(72.5-87)$ & $87.5(86.8-89)$ & 0.033 \\
\hline FVC (L) & $1.7 \pm 0.64$ & $2.7 \pm 0.97$ & 0.007 \\
\hline FVC (\%) & $53.4 \pm 18.6$ & $72.6 \pm 18.3$ & 0.020 \\
\hline FEV1 (L) & $1.1 \pm 0.43$ & $1.9 \pm 0.70$ & 0.004 \\
\hline FEV1 (\%) & $43(31.8-52.8)$ & $70(47.3-76.5)$ & 0.008 \\
\hline FEV1/FVC & $66(62.5-73)$ & $73.5(67-75.3)$ & 0.142 \\
\hline $\mathrm{MEF}_{25-75}(\%)$ & $24(15.5-32)$ & $41(30.3-51.1)$ & 0.020 \\
\hline
\end{tabular}

Table 4. The diagnostic value for the cut-offs determined for PFTs variables

\begin{tabular}{|c|c|c|c|c|}
\hline & $\begin{array}{c}\text { Sensitivity } \\
\%\end{array}$ & $\begin{array}{c}\text { Specificity } \\
\%\end{array}$ & $\begin{array}{c}\text { PPV } \\
\%\end{array}$ & $\begin{array}{c}\text { NPV } \\
\%\end{array}$ \\
\hline \multicolumn{5}{|c|}{ Cut-offs for APAP failure } \\
\hline FEV $1<\% 60$ & 100.0 & 93.8 & 83.3 & 100.0 \\
\hline $\mathrm{MEF}_{25-75}<\% 30$ & 80.0 & 100.0 & 100.0 & 94.1 \\
\hline \multicolumn{5}{|c|}{ Cut-offs for nocturnal hypoxemia } \\
\hline FEV1 $(\mathrm{L})<1.9$ & 84.3 & 69.1 & 63.2 & 87.5 \\
\hline $\mathrm{SpO}_{2}<\% 90$ & 90.2 & 86.4 & 80.7 & 93.3 \\
\hline \multicolumn{5}{|c|}{ Cut-offs for Supplemental $\mathrm{O}_{2}$} \\
\hline FEV1 $(\mathrm{L})<1.5$ & 70.0 & 71.4 & 63.6 & 76.9 \\
\hline FEV $1<\% 50$ & 70.0 & 71.4 & 63.6 & 76.9 \\
\hline
\end{tabular}

Table 5. Correlations between iPAP/ePAP and clinical variables

\begin{tabular}{|c|c|c|c|c|}
\hline & \multicolumn{2}{|c|}{ iPAP } & \multicolumn{2}{|c|}{ ePAP } \\
\hline & rho & p-value & rho & p-value \\
\hline Age & 0.093 & 0.67 & 0.051 & 0.81 \\
\hline BMI $\left(\mathrm{kg} / \mathrm{m}^{2}\right)$ & 0.399 & 0.053 & 0.410 & 0.047 \\
\hline AHI (events/hour) & 0.708 & $<0.001$ & 0.546 & 0.006 \\
\hline ODI & 0.553 & 0.005 & 0.410 & 0.047 \\
\hline Awake $\mathrm{SpO}_{2}$ & -0.303 & 0.150 & -0.168 & 0.433 \\
\hline Minimum $\mathrm{SpO}_{2}$ & -0.453 & 0.026 & -0.113 & 0.599 \\
\hline Mean $\mathrm{SpO}_{2}$ & -0.320 & 0.128 & -0.463 & 0.023 \\
\hline FVC (L) & -0.432 & 0.035 & -0.354 & 0.090 \\
\hline FVC (\%) & -0.345 & 0.098 & -0.268 & 0.206 \\
\hline FEV1 (L) & -0.396 & 0.056 & -0.347 & 0.096 \\
\hline FEV1 (\%) & -0.401 & 0.052 & -0.292 & 0.166 \\
\hline FEV1/FVC & -0.109 & 0.613 & 0.011 & 0.958 \\
\hline $\mathrm{MEF}_{25-75}(\%)$ & -0.231 & 0.278 & -0.177 & 0.409 \\
\hline $\begin{array}{l}\text { BMI: Body mass index, } \\
\text { index, SpO2: Finger pul } \\
\text { expiratory volume in on } \\
\text { and } 75 \% \text { of } \mathrm{FVC}\end{array}$ & $\begin{array}{l}\text { a-hypop } \\
\text { FVC: } \\
\text { IEF }_{25-75}\end{array}$ & $\begin{array}{l}\text { ndex, ODI } \\
\text { d vital capa }\end{array}$ & $\begin{array}{l}\text { xygen d } \\
\text { ty, FEV 1: }\end{array}$ & $\begin{array}{l}\text { rration } \\
\text { eed } \\
\text { ween } 25 \%\end{array}$ \\
\hline
\end{tabular}

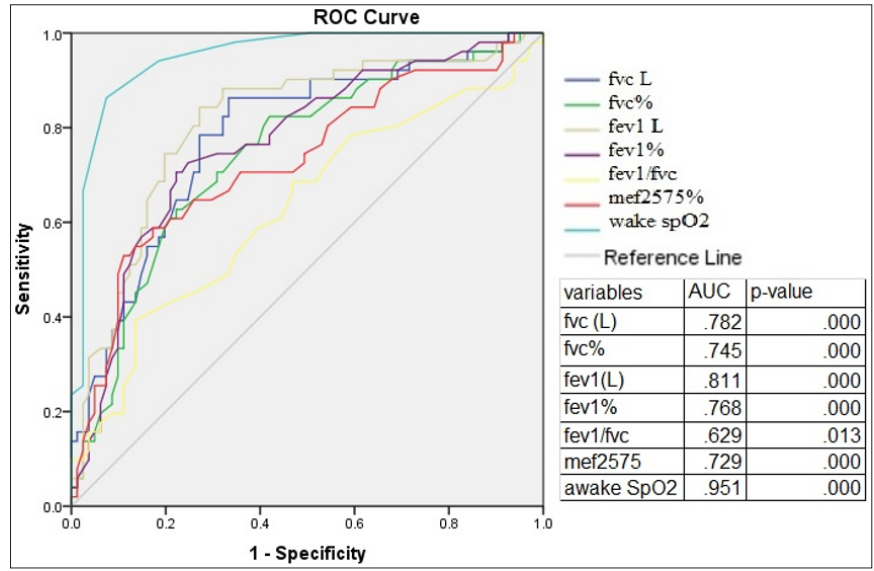

Figure 1. ROC curve analysis for nocturnal hypoxemia

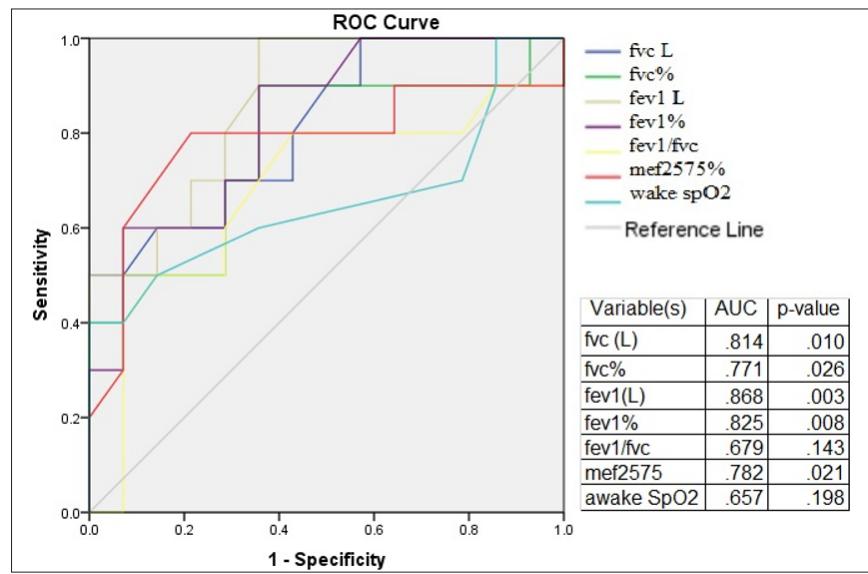

Figure 2. ROC curve analysis for APAP titration failure

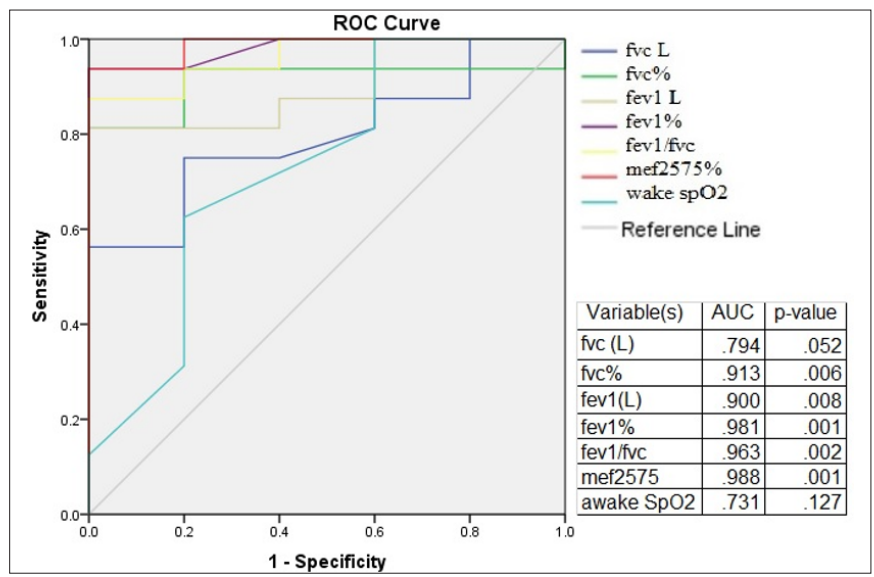

Figure 3. ROC curve analysis for oxygen therapy additional to BPAP

\section{DISCUSSION}

The results of this study show that PFTs parameters can be used to predict polysomnographic findings for patients with obstructive/restrictive disorders. Almost two-thirds of the patients with OSA-related symptoms in this group were observed to have moderate-severe OSAS. In the studies investigating the association of COPD-OSAS (overlap), the rate of OSAS detection in COPD patients was reported between $2.9 \%$ and 
$65.9 \%$ (15). The prevalence in our study is close to the upper limit of this wide range because all patients are symptomatic in terms of OSAS. For this population, nocturnal hypoxemia appears to be quite common in COPD patients and patients with REM-related OSAS. It has been revealed that for $70 \%$ of COPD patients and the majority of patients (85.7\%) using long-term oxygen therapy (LTOT), nasal oxygen support alone is not sufficient to provide nocturnal oxygenation. It is known that especially obese OSAS patients' pulmonary functions are affected (1). On the other hand, Hoffstein et al. argue that there is no relationship between PFTs and OSAS for non-smoking OSAS patients without underlying lung disease (6). In this study, which mostly included patients with overlap syndrome, all of the PFT parameters (FVC\%, FVC (L), FEV1 \%, FEV1 (L), FEV1/FVC, $\mathrm{MEF}_{25-75} \%$ ) were statistically lower for the group with nocturnal hypoxemia. Especially, having an FEV1 value below $1.9 \mathrm{~L}$ and $\mathrm{SpO}_{2}$ awake $<90 \%$ should be admonitory for nocturnal hypoxemia. It has been inferred that nocturnal desaturation in overlap syndrome correlates with daytime $\mathrm{SpO}_{2}$ independent of $\mathrm{BMI}$. For these patients, improvement in daytime $\mathrm{SpO}_{2}$ is achieved with nocturnal CPAP therapy (16).

Abdeyrim et al. (10) pointed that for 263 OSAS patients without expiratory airflow restriction or lung disease, the increase in respiratory resistance and the decrease in functional residual capacity and respiratory conductance were associated with AHI independent of obesity. The decrease in functional residual capacity and increase in pharyngeal collapsibility is a known phenomenon that plays a role in the pathogenesis of OSAS $(4,10)$. Our study reveals the importance of simple spirometric data for OSAS patients with lung disease. It has been proven that there is a statistically significant improvement in airflow restriction with CPAP treatment for patients with a basal FEV1 value below 79.1\% (8). However, for this population with restrictive or obstructive disorders, the participation of the patients in the titration tests and the success of APAP titration are quite low (50\%, $24 \%$, respectively). On the other hand, ABPAP titration success was found to be quite high. Kuklisova et al. (17) inferred that CPAP titration was $23 \%$ unsuccessful in COPD-OSAS overlap syndrome and this was associated with nocturnal hypoxemia and daytime hypercapnia. In addition, they emphasized that FEV1 and FEV1/FVC values were lower for patients whose CPAP titration was not successful. Based on our results in ROC analysis, we believe that it would be appropriate to recommend titration with bilevel devices, especially for patients with FEV $1<60 \%$ and $\mathrm{MEF}_{25-75} \%<30 \%$. Bilevel devices may be useful for patients with reduced $\mathrm{MEF}_{25-75}$ (representing peripheral airways), through alveolar recruitment and pressure support.
In addition to PAP devices, PFT values can be used to predict patients for whom oxygen therapy may be required. It has been inferred that deep nocturnal hypoxemia observed in the coexistence of COPDOSAS, is associated with FEV1/FVC value (18). Oxygen therapy alone in nocturnal hypoxemia does not result in a proven benefit in some conditions, it may also lead to ventilation-perfusion mismatch by preventing hypoxic vasoconstriction (19). Our results show that when PFT results as FEV1 $(\mathrm{L})<1.5$ or $\mathrm{FEV} 1 \%<50 \%$, nocturnal oxygen therapy may be required in addition to PAP devices. Age, BMI, and AHI values were also higher for the group with nocturnal hypoxemia. It is remarkable that despite the statistical similarity in the other clinical parameters only PFT parameters were found to be statistically higher in patients with successful titration.

Titration tests are performed to determine the appropriate pressure or pressure range in PAP treatment. However, mathematical formulas have been proposed to provide a practical way to predict pressure values. Pressures calculated with these formulas are used to determine the initial pressure for treatment or titration. The variables used in these formulas recommended for CPAP are BMI, neck circumference, ESS score, polysomnographic data (such as AHI, RDI, ODI), gender, and the amount of smoking $(20,21)$.

\section{CONCLUSION}

In this study, it was shown that the optimal IPAP value for treatment had a positive correlation with ODI and AHI and a negative correlation with minimum $\mathrm{SpO}_{2}$, as well as a negative correlation with FVC value. Simple spirometric data along with polysomnographic data can also be helpful when determining baseline pressures in BPAP titration for OSAS patients with respiratory dysfunction.

This study contributes to the literature in terms of revealing the importance of PFTs parameters in a sleep clinic and guides the clinical use of these parameters. However, our study only examined cases with PFTs disorder. As mentioned above, the studies examining the relationship between PFTs results and polysomnographic data for people with normal PFTs parameters or the studies comparing these two groups would yield different results.

\section{ETHICAL DECLARATIONS}

Ethics Committee Approval: The ethics committee approval for this study was obtained by the University of Health sciences Keçiören Education and Training Hospital Clinical Studies Ethics Committee (Date: 14/09/2021, Decision No: 2012-KAEK-15/2367). 
Informed Consent: All patients signed the free and informed consent form for the usage of their data.

Referee Evaluation Process: Externally peer-reviewed.

Conflict of Interest Statement: The authors have no conflicts of interest to declare.

Financial Disclosure: The authors declared that this study has received no financial support.

Author Contributions: All of the authors declare that they have all participated in the design, execution, and analysis of the paper and that they have approved the final version

\section{REFERENCES}

1. Carvalho TMDCS, Soares AF, Climaco DCS, Secundo IV, Lima AMJ. Correlation of lung function and respiratory muscle strength with functional exercise capacity in obese individuals with obstructive sleep apnea syndrome. J Bras Pneumol 2018; 44: 279-84.

2. Kairaitis K, Byth K, Parikh R, Stavrinou R, Wheatley JR, Amis TC. Tracheal traction effects on upper airway patency in rabbits: the role of tissue pressure. Sleep 2007; 30: 179-86.

3. Owens RL, Malhotra A, Eckert DJ, White DP, Jordan AS. The influence of end-expiratory lung volume on measurements of pharyngeal collapsibility. J Appl Physiol (1985) 2010; 108: 445-5

4. Zerah F, Harf A, Perlemuter L, Lorino H, Lorino AM, Atlan G. Effects of obesity on respiratory resistance. Chest 1993; 103: 1470-6.

5. Babb TG, Wyrick BL, DeLorey DS, Chase PJ, Feng MY. Fat distribution and end expiratory lung volume in lean and obese men and women. Chest 2008; 134: 704-11.

6. Hoffstein V, Oliver Z. Pulmonary function and sleep apnea. Sleep Breath 2003; 7: 159-65.

7. Akiba Y, Nakano H, Osanai S, et al. Pulmonary function and the pathogenesis of obstructive sleep apnea syndrome. Nihon Kyobu Shikkan Gakkai Zasshi 1995; 33: 1212-8.

8. Schreiber A, Surbone S, Malovini A. The effect of continuous positive airway pressure on pulmonary function may depend on the basal level of forced expiratory volume in 1 second. J Thorac Dis 2018; 10: 6819-27.

9. Marin JM, Soriano JB, Carrizo SJ, Boldova A, Celli BR. Outcomes in patients with chronic obstructive pulmonary disease and obstructive sleep apnea: the overlap syndrome. Am J Respir Crit Care Med 2010; 182: 325-31.

10. Abdeyrim A, Zhang Y, Li N, et al. Impact of obstructive sleep apnea on lung volumes and mechanical properties of the respiratory system in overweight and obese individuals. BMC Pulm Med 2015; 15: 76.

11.Graham BL, Teenbruggen I, Miller MR. Standardization of spirometry 2019 update an official American Thoracic Society and European Respiratory Society technical statement. Am J Respir Crit Care MedVol 2019; 200: e70-e88.

12. Berry RB, Brooks R, Gamaldo CE, et al. for the American Academy of Sleep Medicine. The AASM Manual for the scoring of sleep and associated events: rules, terminology, and technical specifications, Version2.3 2008 www.aasmnet.org. Darien, Illinois: American Academy of Sleep Medicine.

13. Ramsey R, Mehra R, Strohl KP. Variations in physician interpretation of overnight pulse-oximetry monitoring.Chest 2007; 132: 852-9.
14. Kushida CA, Chediak A, Berry RB, et al. Clinical Guidelines for the Manual Titration of Positive Airway Pressure in Patients with Obstructive Sleep Apnoea. Positive Airway Pressure Titration Task Force of the American Academy of Sleep Medicine. J Clin Sleep Med 2008; 4: 157-71.

15. Shawon MS, Perret JL, Senaratna CV, Lodge C, Hamilton GS, Dharmage SC. Current evidence on prevalence and clinical outcomes of co-morbid obstructive sleep apnea and chronic obstructive pulmonary disease: a systematic review. Sleep Med Rev 2017; 32: 58-68

16. Lacedonia D, Carpagnano GE, Aliani $\mathrm{M}$,et al. Daytime $\mathrm{PaO}_{2}$ in OSAS, COPD and the combination of the two (overlap syndrome). RespirMed 2013; 107: 310-6.

17. Kuklisova Z, Tkacova R, Joppa P, Wouters E, Sastry M. Severity of nocturnal hypoxia and daytime hypercapnia predicts CPAP failure in patients with COPD and obstructive sleep apnea overlap syndrome. Sleep Med 2017; 30: 139-45.

18. Sanders MH, Newman AB, Haggerty CL, et al. for the Sleep Heart Health Study. Sleep and sleep disordered breathing in adults with predominantly mild obstructive airway disease. Am J Respir Crit Care Med 2003; 167: 7-14.

19. Owens RL. Supplemental oxygen needs during sleep. Who benefits? Respir Care 2013; 58: 32-47.

20. Makarawate P, Senthong V, Sawanyawisuth K. Cpap Pressure by Cpap Titration or Prediction Formula. J Sleep Disorders Ther 2013, 2: 4 .

21. Camacho M, Riaz M, Tahoori A, Certal V, Kushida CA. Mathematical equations to predict positive airway pressures for obstructive sleep apnea: a systematic review. Sleep Disord 2015; 2015: 293868. 